\title{
UNCONVENTIONAL SMALL-SCALE BIOGAS PRODUCTION WITH REDUCED LOCAL IMPACT
}

\author{
ELENA CRISTINA RADA ${ }^{1}$, LUCA COSTA ${ }^{2}$, CECILIA PRADELLA ${ }^{2}$, LUCA ADAMI $^{1,2}$, \\ MARCO SCHIAVON $^{2}$, ELENA MAGARIL ${ }^{3} \&$ VINCENZO TORRETTA $^{1}$ \\ ${ }^{1}$ University of Insubria, Department of Theoretical and Applied Sciences, Varese, Italy. \\ ${ }^{2}$ University of Trento, Department of Civil, Environmental and Mechanical Engineering, Trento, Italy. \\ ${ }^{3}$ Ural Federal University, Department of Environmental Economics, Ekaterinburg, Russian Federation.
}

\begin{abstract}
One of the problems of food waste management is the acceptability of the treatment plants at local level because of the risk of odours. Anaerobic digestion as first step before composting has contributed to solve this problem, but, in the sector, it remains an opposition to large plants. That affects also food waste anaerobic digestion: people's perception is that the stream coming at the gate of the plant is not theirs. The present paper shows an alternative to the conventional approach. The aim is to reduce the scale of the intervention giving a solution also to small municipalities or to an aggregation of small municipalities. The basic idea is suitable for adaptations depending on the local availability of manure and other plants specialised on wastewater. The integrability of these plants allows reducing the costs for treating secondary streams to be managed, as discussed in the article. The extreme technological scenario is based on an anaerobic digester with unconventional pre-treatment of food waste and energy recovery, on a hydro-thermal carbonisation reactor for manure, on an ammonia separator for product recovery (by stripping), on a $\mathrm{CO}_{2}$ separator (from off-gases), on a hydro-biochar flusher for opening to land application and on mechanised small-scale composters for small communities. The principles of the circular economy are adopted, but the economic balance is affected by the transport costs of the products. The suitability of this approach to medium income countries is discussed too.

Keywords: anaerobic digestion, circular economy, decentralization, discarded biomass, environmental sustainability, food waste, HTC, manure, renewable energy, waste management.
\end{abstract}

\section{INTRODUCTION}

Biodegradable waste is an important topic worldwide because its potential to be used for producing energy [1-3] but also because, when non optimised, this stream of waste causes important impacts: when put in a landfill, even a sanitary landfill, fugitive emissions of biogas have a high impact as the contained methane is a greenhouse gas (GHG) [4-6]. The attention to this problem is different from Country to Country and can significantly change depending on the way of collecting waste [7-9]. According to the Italian approach, coming from the European Union (EU) vision on waste management, each municipality is in charge of Municipal Solid Waste (MSW) collection. In this context, source separation is compulsory as part of EU waste management strategies. Focusing on the collection of the organic fraction of MSW (OFMSW), named also food waste, small municipalities must formalise consortia to reach an amount of collected waste suitable to make economically sustainable its local collection and transport to a treatment plant. In optimised scenarios, the obtained stream is sent generally to a conventional centralised treatment in an anaerobic digestion (AD) plant that is more and more substituting direct composting (and avoids food waste landfilling). One of the consequences of this centralised approach is that people think that most of the OFMSW locally treated is not theirs, it is from others [10]. That causes the well-known difficulties of plant construction related to the concept of NIMBY (Not-In-My-Back-Yard), once limited to landfilling and incineration $[11,12]$ but today involving also biological treatment plants. The 
present article wants to propose a possible unconventional solution to make AD more acceptable locally. Moreover, dealing with small municipalities, in many parts of Italy (and not only) the territory is characterised by the presence of industrial activities that belong to the zoo-technical sector. For that reason, a significant amount of manure from pigs, cows, etc. can be used to generate energy [13-16], but also can cause problems, at least of odour and nitrogen load on land (when manure is spread on the ground) [17-18]. Here we can find a second aim of the present article: integrating manure management with AD through an innovative approach that can solve the problem of the excess of nitrogen on land and decreases odour generation. This innovative approach is based on an integration of $\mathrm{AD}$ with a reactor of hydro-thermal carbonisation (HTC) specialised in the treatment of zoo-technical manure [19]. Additional integrations with reactors of ammonia stripping and mechanised small-scale composting offer the opportunity to be more coherent with the concepts of Circular Economy (CE) and practically to be not depending on large and far plants.

The proposed innovative integration of AD and HTC is based on a context that in EU has demonstrated that AD is already well developed and HTC is an emerging technology. A state of the art is presented in a part of the article referred mostly to EU. However, the approach, with adequate simplifications, can be interesting also for medium income countries, as explained in the discussion section. Some economic considerations complete the article.

\section{MATERIAL AND METHODS}

The development of the present article followed the steps listed below:

- Short focus on the technologies for OFMSW present in EU and specifically in Italy (specifically AD, HTC and mechanised small-scale composting).

- Definition of the integrated innovative approach for the treatment of OFMSW alone or OFMSW and manure (general case, EU context)

- Finding of a case study of interest (EU context, small municipalities consortia)

- Adapting the general scheme to the local context, seeking additional inputs

- Assessment of the streams of interest (only OFMSW in the present article)

- Defining design parameters (only for OFMSW) at feasibility level

- Discussing the replicability of the approach in EU and Non-EU contexts

In the present article, AD is referred especially to OFMSW. Information about the amount of waste produced is a fundamental starting point: in many EU contexts, information is easily available from the local municipalities and from the regional environmental agencies. The knowledge of how the wastes in collected and which strategy is used by municipality to collect are fundamental to quantify the stream of OFMSW. Once the OFMSW is collected, it is necessary to know its physical and chemical characteristics, like moisture and volatile solid content (VS) [20]. From the amount of water, derives the amount of total solids (TS). Pre-treatment and AD strategies depend on the quantity of water. Density is a parameter often used to calculate and to analyse the behaviour of digesters. Waste with a higher density contains less unwanted substances and material [21]. Correlation between OFMSW and methane generation depends not only on the characteristics of the waste but also on design parameters, pre-treatment and on process conditions. Studies [22] have shown that hydrolysis is the slowest phase of $\mathrm{AD}$, and consequently that limits the rate of the entire process. There is a need to bypass the slowness of degradation of complex waste to use a hydraulic retention time (HRT) lower than the typical AD processes [23]. 


\section{RESULTS AND DISCUSSION}

The sector of AD in EU is described as follows. In 2017, the share of renewable energy in the EU energy mix has reached $17.52 \%$ (EU28), while the target for the 2020 is fixed at $20 \%$ [24]. The average increase over the period 2014-2017 was lower than the needed. Therefore, it is necessary to improve the percentage of Renewable Energy Sources (RES) to reach the goal in these years. AD is an option that can help. The sector of AD slightly rose in 2017 [25]. The main producer countries are Germany (7844.6 ktoe), United Kingdom (2718.9 ktoe), Italy (1897.7 ktoe) and France (899.5 ktoe). Generally, in 2017, the share of biogas in renewable electricity generation in the EU 28 was about $63.4 \mathrm{TWh}$, split into two main producers: electricity only plants (32.6\%) and CHP plants (67.4\%). The production of electricity from biogas from AD amounts to $8.3 \mathrm{TWh}$ (13\% of the total EU biogas production) [26]. From the technical point of view, this sector has evolved significantly allowing an optimised management of conventional plants.

The sector of HTC in EU is described as follows. HTC can be seen as a 'new technology' applied on biowaste. HTC is a recent innovative process and starts to be developed only some years ago [27]. Nowadays there are more than 200 companies and organisations distributed worldwide working on this topic. The majority of the applications of patents on HTC were registered in China, USA and Germany. The whole EU 28 has about 30\% of the patents released (Germany 10\%) [28]. At the end of June 2010, the first industrial plant in the world able to carbonize continuously a variety of biomass was built. The EU started a new project in November 2013 called NEWAPP [28] ('New technological applications for wet biomass waste stream products') with the aim to coordinate and valuate the EU biomass industry and to test the best HTC technology options and explore the different applications of the new products. NEWAPP demonstrated that HTC is a sustainable technology, able to upgrade a wide range of organic residues into a high value carbonaceous product, ready for the commercial take off. Then EU is ready to improve HTC technology, from pilot scale to industrial scale.

The sector of small-scale mechanised composting is described as follows. In the EU strategy, composting stands like a fundamental tool for an efficient use of sources. In this context, small-scale composting is an example of proximity in a frame of circular economy: the production of compost occurs directly on site, by using the organic waste produced in the community or municipality. This technology works with small electromechanical machines, where the aerobic process is maintained and accelerated continuously by a system that moves wastes and lets air in [29]. This kind of machines are fully automatic and can be classified into single or double chamber, in relation to material handling: in the first type all the process occurs in a single reactor, while in the second, the process is split in two phases, act phase and curing phase. Nowadays the use of small-scale mechanised composting to treat all or part of organic wastes in a municipality is quite limited. First of all, there is a technological limit, because these machines work with a low amount in input, with a processing capacity of about $1600 \mathrm{ton} / \mathrm{y}$. Then these systems work in discontinuous/semi-continuous stage, with a minimum HRT of 2 weeks. If the first problem can be overcome with more composters working in parallel, so they have different loading times, the second problem is the real limit in the implementation of this technology. Indeed, due to high HRT, a biowaste loading at different times could compromise the quality of the outgoing compost. A two-chamber system can help to overcome the problem, but these machines, at the moment, have a very limited processing capacity. More studies are necessary for the implementation of this technology in a medium scale and related to the present report, where the solid phase of OFMSW collected by a municipality exit from the separator before the $\mathrm{AD}$ reactor. 
The presented overview demonstrates that the units composing the integrated approach area already available or can be made available in a short time. Concerning the overall approach, the pre-treatment involved in the project consists of two main phases: in the first one, OFMSW is heated and diluted with water. In the second stage, a centrifuge separates a liquid phase with readily available organic matter from the biowaste. The thermal treatment of the OFMSW results in an increase in total supernatant COD concentration, total and soluble: in the first pre-treatment a fermentation occurs, performed at the same heat of the reactor. The dilution with water is fundamental for a better separation of solid and liquid fractions in the centrifuge, as increases the amount of RBCOD in the liquid phase [23]. The dilution ratio of the wastes determines the quantity of liquid separation that occurs in the second pretreatment. Anyway, in the liquid phase there is mainly RBCOD: the aim is to convert it into biogas and due to its fast biodegradability, it is easy to convert it quickly. The reactor chosen is a one-stage continuous stirred tank reactor (CSTR) [30]. The main parameter that controls the reactor is the organic loading rate (OLR): it indicates how much organic matter can be fed into the digester, per volume and time unit. In literature, OLR has a wide range of application: Khalid et al. [31] saw that OLR can vary from 2.6 to $43\left(\mathrm{~kg}_{\mathrm{VS}} \mathrm{m}^{-3} \mathrm{~d}^{-1}\right)$ depending on kind of digesters and substrates. Having a liquid phase with a high amount of RBCOD allows having lower HRT and higher OLR because the organic matter is already in a soluble phase and has a fast conversion yielding into biogas.

The original integrated approach, presented in this article, is reported in Fig. 1 and refers only to the OFMSW treatment at small scale. Additional integrations are described below.

The concept of the scheme is the following:

- OFMSW must be pre-treated by a double step; the scheme shows a pre-treatment 1 based on heating; dilution (not drawn in Fig. 1) could be taken into account to favour the following RBCOD extraction [23];

- The second pre-treatment is a separation step, extracting a liquid reach in RBCOD and leaving a stream mostly solid that is less putrescible;

- The liquid reach in RBCOD is sent into an $\mathrm{AD}$ reactor with a lower hydraulic retention time, compared to the conventional one;

- The effluent of locally treated civil wastewater may be used to partially dilute the input of $\mathrm{AD}$, to adjust the organic load;

- Biogas can be sent to an engine performing co-generation;

- Heat from engine cooling can be used for heating pre-treatment and AD;

- Composting is performed with an overall reduction of electricity consumption for aeration, as RBCOD is extracted before it;

- The liquid effluent of AD must be treated.

A context where the approach could be adapted efficiently was found in the North of Italy. It is the case of Oppeano and surroundings (close to Verona). The case of Oppeano is significantly favourable as:

- The Municipality is active in the Covenant of Major network [32].

- The Municipality is already in a Consortium of municipalities for a coordinate waste collection.

- There is a high-quality separated collection of OFMSW.

- There is manure generation locally, presently not treated. 


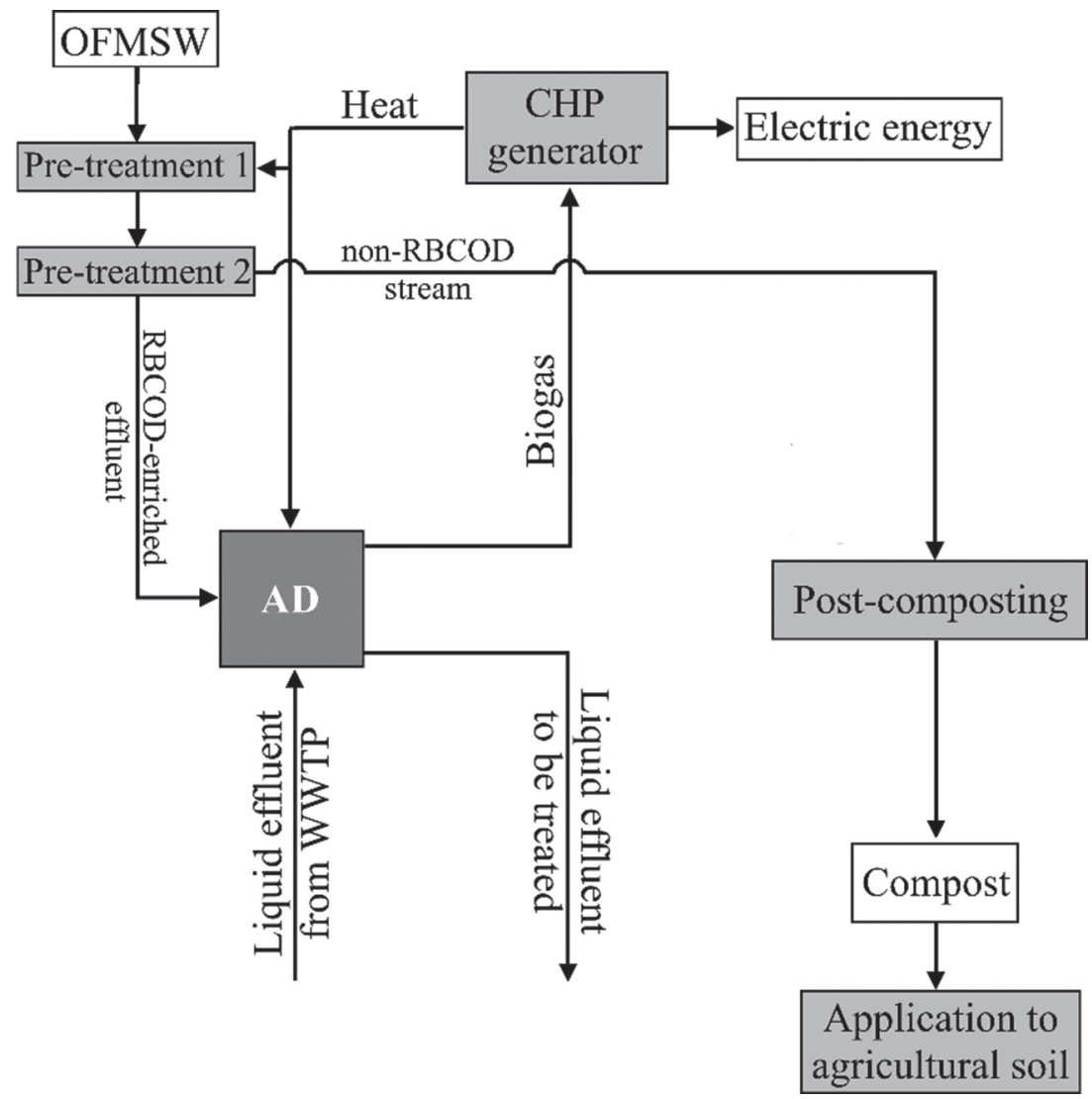

Figure 1: Flowchart of the general integrated scenario aimed to OFMSW unconventional treatment.

- There is availability of land for treated discarded biomass spreading.

- There is attention to the local generation of electricity from renewable sources.

The waste collection consortium includes 20 municipalities, with a total amount of inhabitants of 91,234 (in 2017). The type of waste collection operated is a source separated kerbside collection. The percentage of selective collection is, in 2017, higher than 76\%. Table 1 reports data of OFMSW in the area [33]. The high rate of separate collection allows having a high quality OFMSW as input in the plant. The OFMSW main characteristics are: TS [\%OFMSW] = 30\%; VS [\% TS] 90\% [3]; COD/VS = 2 for liquid and solid phases. The density is assumed similar to the one of water. The design concepts are mainly based on a $\mathrm{PhD}$ research [23]. The first pre-treatment step consists on a thermal treatment and a dilution of waste. The OFMSW are heated at $35^{\circ} \mathrm{C}$ for 6 hours and the dilution ratio applied is $1: 1.5$ (waste:water): these conditions allow to have an higher content of COD in the liquid phase after the centrifugation step. The amount of COD extracted is about 35\% of the total COD found in the OFMSW entering the system. $80 \%$ of the extracted COD consists in RBCOD. This condition allows a faster conversion of organic substances, in the first part of AD process. The supernatant proved to be a viable substrate for $\mathrm{AD}$ since it contained a sufficient nutrients concentration 
Table 1: OFMSW in the case study.

\begin{tabular}{ccccc}
\hline$\#$ & Municipality & Pop. [ab] & OFMSW $[\mathrm{Mg}]$ & Per-capita $\left[\mathrm{kg} \mathrm{ab}^{-1} \mathrm{y}^{-1}\right]$ \\
\hline 1 & Angiari & 2229 & 193.74 & 86.9 \\
2 & Belfiore & 3102 & 226.4 & 73.0 \\
3 & Casaleone & 5824 & 429.4 & 73.7 \\
4 & Concamarise & 1068 & 83.89 & 78.5 \\
5 & Erbè & 1850 & 128.54 & 69.5 \\
6 & Gazzo Veronese & 5380 & 368.12 & 68.4 \\
7 & Isola della Scala & 11563 & 1098.27 & 95.0 \\
8 & Isola Rizza & 3280 & 302.48 & 92.2 \\
9 & Nogara & 8607 & 781.24 & 90.8 \\
10 & Nogarole & 3646 & 329.44 & 90.4 \\
11 & Oppeano & 9876 & 1008.76 & 102.1 \\
12 & Palù & 1256 & 112.67 & 89.7 \\
13 & Ronco all'Adige & 6000 & 487.96 & 81.3 \\
14 & Roverchiara & 2779 & 259.79 & 93.5 \\
15 & S.Pietro di Mor. & 3017 & 242.95 & 80.5 \\
16 & Salizzole & 3790 & 282.41 & 74.5 \\
17 & Sorgà & 3038 & 222.6 & 73.3 \\
18 & Terrazzo & 2236 & 179.14 & 80.1 \\
19 & Trevenzuolo & 2738 & 207.88 & 75.9 \\
20 & Vigasio & 9955 & 797.12 & 80.1 \\
\hline & Total & 91234 & 7743 & 849 \\
\hline
\end{tabular}

[23]. The second pre-treatment consists on a centrifuge that separates two main streams: one liquid phase rich in RBCOD and one semi-solid phase. The first goes to AD, instead the second goes to a post-composting process $\mathrm{AD}$ is set to take place at $35^{\circ} \mathrm{C}$. Due its fast degradation, the HRT in the digester is fixed in 4 days, and thanks to the speed of conversion, the OLR is higher than typical CSTR one (about $10 \mathrm{~kg}_{\mathrm{VS}} \mathrm{m}^{-3} \mathrm{~d}^{-1}$ in the standard case). The specific gas production rate (SGP) obtained was near to $0.8 \mathrm{Nm}^{3} \mathrm{~kg}_{\mathrm{Vs}}{ }^{-1}$ added and the anaerobic treatment achieved VS removal efficiencies of 95\% [23]. All these parameters give a compact AD reactor: the volume value depends on the dilution applied to the input of the reactor to decrease OLR. This choice requires a lab-scale test to optimise the approach.

In the case-study context, the following modifications/adaptations could be taken into account:

- HTC could treat manure locally generated; the advantage is to avoid emissions of ammonia and odours when applied directly to land, as the treatment allows producing hydro-biochar, rinsed adequately to be stable, non-odorigenous and suitable to land application;

- The gaseous stream from HTC is suitable for a stripping of ammonia and for the extraction of $\mathrm{CO}_{2}$ (thanks their high concentration in the off-gas);

- Post-composting could be performed automatically in a small-scale mechanised device to avoid distance transportation; 
- The local presence of an SBR for industrial wastewater opens to a co-treatment of the effluent from AD (as the stream flow-rate is very low);

- The local presence of a civil wastewater treatment plant makes available treated wastewater to dilute the AD input, if the resulting organic load is too high. Treated wastewater could be used also for the first step of OFMSW pre-treatment to favour RBCOD extraction; however, the approach based on dilution could be substituted by an optimisation of a mechanical approach of separation of OFMSW as is;

It must be underlined that all the needed plants described in Fig. 2 are already present in the case-study or can be constructed in the same site. Biomethane extraction is not proposed because of the reduced scale of the plants.

A preliminary dimensioning of the system of Fig. 2 is going to be part of a proposal to EU for co-financing a LIFE+ project. For this reason, details will not be presented in this article.

Concerning the economic aspects, the following considerations are resumed in Table 2. Safety and security are seen as an additional cost to be faced with, where necessary.

Concerning the replicability of the approach, some considerations can be made. The first configuration (Fig. 1) could be of interest in developing countries, where the main source of waste is composed by organic material. However, the required technological level should limit the adoption to middle-income countries. Moreover, a source separation of OFMSW should be implemented even accepting impurities in the separated stream. In this case, conventional $\mathrm{AD}$ approaches are critical for settling phenomena in the $\mathrm{AD}$ reactor. In the presented case AD operates on a liquid stream. Concerning other characteristics:

- it treats OFMSW reducing the amount of waste in landfill; that means less greenhouse gas impact;

- the final product is useful for the agriculture as a soil improver;

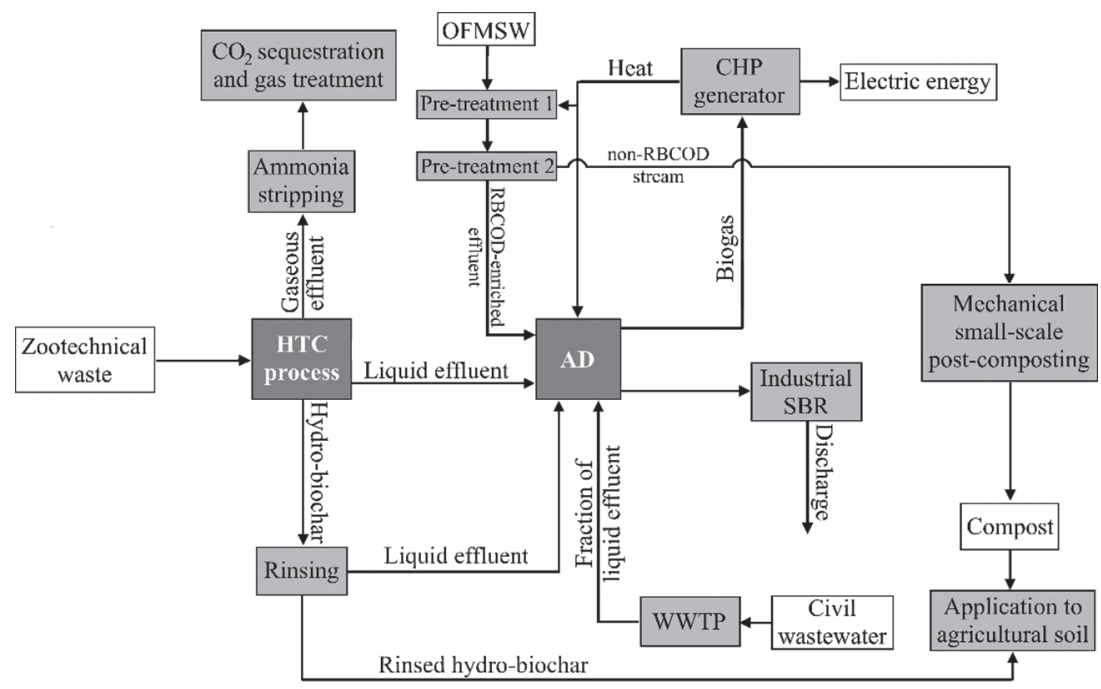

Figure 2: Flowchart of the contextualised integrated scenario aimed to OFMSW and manure unconventional treatment. 
Table 2: Zooming on economic aspects of the approach.

\begin{tabular}{|c|c|}
\hline \multicolumn{2}{|c|}{ Products and market } \\
\hline Electricity & It comes from renewable sources; public incentives possible in EU. \\
\hline Heat & Internal use; indirect saving. \\
\hline Hydro-biochar & $\begin{array}{l}\text { More acceptable than direct application of manure (odor and emissions } \\
\text { reduction should be monetized) }\end{array}$ \\
\hline Compost & $\begin{array}{l}\mathrm{km} 0 \text { application possible through mechanized systems for small } \\
\text { communities; that makes it more acceptable }\end{array}$ \\
\hline Ammonia & km 0 exploitation unlikely \\
\hline $\mathrm{CO}_{2}$ & $\begin{array}{l}\mathrm{km} 0 \text { exploitation unlikely; sequestration option more and more } \\
\text { interesting economically }\end{array}$ \\
\hline \multicolumn{2}{|c|}{ Transport effects on costs } \\
\hline Electricity & Exploited locally (less transport losses) \\
\hline Heat & Exploited locally \\
\hline Hydro-biochar & Exploited locally (less mass to be transported \\
\hline Compost & Exploited locally (differently from conventional approaches) \\
\hline Ammonia & Possibly to be transported \\
\hline $\mathrm{CO}_{2}$ & Possibly to be transported \\
\hline \multicolumn{2}{|c|}{ Safety and security aspects } \\
\hline Electricity & Conventional approach \\
\hline Heat & Conventional approach \\
\hline Hydro-biochar & HTC is pressured and high temperature heated; expertise is required \\
\hline Compost & Conventional approach \\
\hline Ammonia & Stripping is heated and has extreme $\mathrm{pH}$ values; expertise is required \\
\hline $\mathrm{CO}_{2}$ & Depending on the option adopted \\
\hline
\end{tabular}

- the energy produced can be used in the first treatment steps to reduce energy gap (moreover, the small-scale approach allows having electricity available in decentralized areas);

- the small scale of the system allows on-site construction and reduces transport costs.

In spite of the advantage of having $\mathrm{AD}$ on a liquid stream, in order to make this system more suitable for the context, a pre-treatment should be adopted in order to filter the organic matter from the impurities such as plastic or inert materials. To this concern, industrial research should set a system to work on OFMSW with impurities.

At the end, an awareness and information plan for the population should be conducted showing the importance and opportunities of waste management for the long-term sustainability. Considering these factors, this technology could be installed as a context-aware solution for middle-income countries with the proposed arrangements.

\section{CONCLUSIONS}

The integration of small units for discarded biomass valorisation has been described in this article. Novelties concern the high integration of the system, with some advantages: 
- Less odour (direct manure spreading is avoided).

- Less emissions (ammonia released from land application of conventional manure reacts with NOx in the atmosphere and generates secondary particulate; this problem is reduced through the proposed system).

- Less biomass transport compared with large plants scenarios (the proposal is close to a zero km strategy on discarded biomass).

- Less loss of electricity from transport in the grid, because the small scale allows (potentially) full local consumption.

- Compliance with circular economy principles.

- Less Nitrogen to land (as extracted by stripping, as a product)

- Opportunities for $\mathrm{CO}_{2}$ reduction if the extracted $\mathrm{CO}_{2}$ is adequately managed.

For a full exploitation of the approach, a specific project is going to be submitted to EU. Replications also out of an EU context are expected.

\section{REFERENCES}

[1] Campuzano, R. \& González-Martínez, S., Characteristics of the organic fraction of municipal solid waste and methane production: A review. Waste Management, 54, pp. 3-12, 2016. https://doi.org/10.1016/j.wasman.2016.05.016

[2] Fehr, M. \& Arantes, C.A., Making a case for recycling biodegradable municipal waste. Environment Systems and Decisions, 35(4), pp. 483-489, 2015. https://doi.org/10.1007/ s10669-015-9568-z

[3] Andreottola, G., Ragazzi, M., Foladori, P., Villa, R., Langone, M. \& Rada, E.C., The unit intregrated approach for OFMSW treatment. UPB Scientific Bulletin, Series $C$ : Electrical Engineering, 74(1), pp. 19-26, 2012.

[4] Sánchez, C., de la Fuente, M.D.M., Narros, A., del Peso, I. \& Rodríguez, E., Comparison of modeling with empirical calculation of diffuse and fugitive methane, emissions in a Spanish landfill. Journal of the Air and Waste Management Association, 69(3), pp. 362-372, 2019. https://doi.org/10.1080/10962247.2018.1541029

[5] Broun, R. \& Sattler, M., Greenhouse gas emissions from conventional vs. bioreactor landfills. Proceedings of the Air and Waste Management Association's Annual Conference and Exhibition, 1, pp. 249-255, 2015.

[6] Cocarta, D.M., Rada, E.C., Ragazzi, M., Badea, A. \& Apostol, T., A contribution for a correct vision of health impact from municipal solid waste treatments. Environmental Technology, 30(9), pp. 963-968, 2009. https://doi.org/10.1080/09593330902989958

[7] Rada, E.C., Zatelli, C., Cioca, L.I. \& Torretta, V., Selective collection quality index for municipal solid waste management. Sustainability, 10(1), p. 257, 2018. https://doi. org/10.3390/su10010257

[8] Ferreira, F., Avelino, C., Bentes, I., Matos, C. \& Teixeira, C.A., Assessment strategies for municipal selective waste collection schemes. Waste Management, 59, pp. 3-13, 2017. https://doi.org/10.1016/j.wasman.2016.10.044

[9] de Oliveira, T.B. \& Galvão Junior, A.C., Municipal planning in solid waste management and organization of selective collection. Engenharia Sanitaria e Ambiental, 21(1), pp. 55-64, 2016. https://doi.org/10.1590/s1413-41520201600100155929

[10] Lober, D.J., Why not here? The importance of context, process, and outcome on public attitudes toward siting of waste facilities. Society and Natural Resources, 9(4), pp. 375-394, 1996. https://doi.org/10.1080/08941929609380981 
[11] Zheng, G. \& Liu, W., Same projects, different endings-Comparative case studies on NIMBY facility construction in Beijing. Cities, 73, pp. 63-70, 2018. https://doi. org/10.1016/j.cities.2017.10.010

[12] Salleh, A.H., Ahamad, M.S.S., Yusoff, M.S. \& Aziz, H.A., Multiple criteria landfill site selection method incorporating the NIMBY factors. AIP Conference Proceedings, 1892, p. 130003, 2017. https://doi.org/10.1063/1.5005759

[13] Esteves, E.M.M., Herrera, A.M.N., Esteves, V.P.P. \& Morgado, C.D.R.V., Life cycle assessment of manure biogas production: A review. Journal of Cleaner Production, 219, pp. 411-423, 2019. https://doi.org/10.1016/j.jclepro.2019.02.091

[14] Svanberg, M., Finnsgård, C., Flodén, J. \& Lundgren, J., Analyzing animal waste-toenergy supply chains: The case of horse manure. Renewable Energy, 129, pp. 830-837, 2018. https://doi.org/10.1016/j.renene.2017.04.002

[15] Yang, Q., Wang, H., Larson, R. \& Runge, T., Comparative study of chemical pretreatments of dairy manure for enhanced biomethane production. BioResources, 12(4), pp. 7363-7375, 2017. https://doi.org/10.15376/biores.12.4.7363-7375

[16] Antognoni, S., Ragazzi, M., Ionescu, G., Passamani, G., Zanoni, S., Rada, E.C. \& Torretta, V., Respirometric index as a tool for biogas generation production from poultry manure. Management of Environmental Quality: An International Journal, 27(3), pp. 269-280, 2016. https://doi.org/10.1108/meq-04-2015-0052

[17] Nykänen, A.M., Hämäläinen, N., Kostia, S., Mikola, J. \& Romantschuk, M., Reduction of odorants in swine manure by carbohydrate and bacterial amendments. Journal of Environmental Quality, 39(2), pp. 678-685, 2010. https://doi.org/10.2134/jeq2008.0530

[18] Gennen, J. \& Luxen, P., Estimated loss of nitrogen via ammonia volatilisation during spreading of liquid manure on permanent grasslands. Fourrages, 2015(224), pp. 265-268, 2015.

[19] Huang, W., Zhao, Z., Yuan, T., Huang, W., Lei, Z. \& Zhang, Z., Low-temperature hydrothermal pretreatment followed by dry anaerobic digestion: A sustainable strategy for manure waste management regarding energy recovery and nutrients availability. Waste Management, 70, pp. 255-262, 2017. https://doi.org/10.1016/j.wasman.2017.09.011

[20] Campuzano R. \& González-Martínez, S., Characteristics of the organic fraction of municipal solid waste and methane production: A review. Waste Management, 54, pp. 3-12, 2016. https://doi.org/10.1016/j.wasman.2016.05.016

[21] Forster-Carneiro, T., Pérez, M. \& Romero, L.I., Thermophilic anaerobic digestion of source-sorted organic fraction of municipal solid waste. Bioresource Technology, 99(15), pp. 6763-6770, 2008. https://doi.org/10.1016/j.biortech.2008.01.052

[22] Amani, T. \& Nosrati M., Anaerobic digestion from the view point of microbiological, chemical, and operational aspects - A review. Environmental Reviews, 18(1), pp. 255-278, 2010. https://doi.org/10.1139/a10-011

[23] Sibisi, N.N.S., Development of an Anaerobic Digestion Strategy for the OFMSW Treatment and its Co-Digestion with Sewage Sludge, $\mathrm{PhD}$ Thesis, University of Trento, $\mathrm{PhD}$ in Environmental Engineering, XVIII Cycle - 2005.

[24] European Commission, Report from the commission to the European Parliament, the Council, the European Economic and Social Committee and the Committee of the Regions, Renewable Energy Progress Report: Brussels, 2019.

[25] Eurobserv'ER, The State of Renewable Energies in Europe, 18th EurObserv'ER Report, 2018 Edition.

[26] GSE, Rapporto statistico 2017 fonti rinnovabili (in Italian), December 2018. 
[27] Heidari, M., Dutta, A., Acharia, B. \& Mahmud S., A review of the current knowledge and challenges of hydrothermal carbonization for biomass conversion. Journal of the Energy Institute. https://doi.org/10.1016/j.joei.2018.12.003

[28] NEWAPP, Industrial Scale Hydrothermal Carbonization: New applications for wet biomass waste, June 2016, www.newapp-project.eu/en/ (accessed 12 April 2019).

[29] Landolfo P.G., Stato dell'arte nel compostaggio di comunità (in Italian) Ecomondo 2015.

[30] Matheri, A.N., Mbohwa, C., Belaid, M., Seodigeng, T. \& Ngila, J.C., Design model selection and dimensioning of anaerobic digester for the OFMSW. Lecture Notes in Engineering and Computer Science, 2226, pp. 846-851, 2016.

[31] Khalid, A., Arshad, M., Anjum, M., Mahmood, T. \& Dawson, L., The anaerobic digestion of solid organic waste. Waste Management, 31(8), pp. 1737-1744, 2011. https:// doi.org/10.1016/j.wasman.2011.03.021

[32] The EU Covenant of Mayors for Climate \& Energy, www.covenantofmayors.eu/en/. (accessed April 12, 2019).

[33] Arpav, Rapporto rifiuti urbani, Produzione e Gestione 2017 (in Italian) Ed. 2018. 